\title{
A política monetária norte-americana e o recente ciclo de negócios
}

Flávio A. C. Basílio*

\section{Introdução}

Sendo os Estados Unidos a maior economia do mundo, é importante ter em mente que a condução da política monetária americana é capaz de afetar de forma positiva, ou negativa todas as economias do mundo. Além disso, a condução da sua política monetária provoca efeitos econômicos e financeiros significativos capazes de influenciar o processo de tomada de decisões por parte dos agentes econômicos. Dado isso, o presente artigo tem como principal objetivo analisar o comportamento recente da política monetária americana e seus possíveis desdobramentos.

\subsection{Determinantes teóricos da política monetária americana}

$\mathrm{Na}$ teoria econômica sabe-se que a política monetária é capaz de influenciar a performance de variáveis econômicas como inflação, produto e emprego. Desta forma, a política monetária é conduzida pelo sistema de Reserva Federal, em que o Banco Central Norte-americano utiliza o instrumental da taxa de juros de curto prazo para influenciar a demanda agregada. De acordo com o Federal Reserve Act de 1977, a política monetária dos Estados Unidos deve ser conduzida com base em dois objetivos: promover uma política de pleno-emprego no longo prazo e garantir a estabilidade de preços.

No entanto, a economia atravessa períodos em que o produto e o emprego estão abaixo do seu nível de longo-prazo. Assim, mesmo admitindo que a política monetária não é capaz de afetar estas duas variáveis no longo-prazo, o Federal Reserve utiliza o instrumento da taxa de juros para afetá-las no curto prazo e, desta forma, evitar picos e vales muito acentuados ao longo da trajetória de estabilização.

Acrescenta-se que o outro objetivo do Federal Reserve é garantir a estabilidade de preços, entendida como um ambiente de baixa inflação, em que as famílias e as firmas possam tomar suas decisões financeiras sem se preocupar com as possíveis trajetórias da inflação. No entanto, como base nas versões modernas da Curva de Phillips, a taxa de inflação só pode ser reduzida se a economia durante um certo período de tempo crescer abaixo do seu produto potencial e o nível de emprego estiver abaixo do "nível natural".

\footnotetext{
* Mestrando em Desenvolvimento Econômico pela UFPR. Endereço eletrônico: flaviobasilio@ufpr.br
} 
Os modelos econômicos que incorporam o conceito da Curva de Phillips levam em consideração o mecanismo de transmissão de mudanças não antecipadas em algum dos componentes da demanda agregada sobre o sistema econômico. Os chamados choques de demanda conduzem a economia a operar com um produto acima de seu nível potencial, o que gera pressões inflacionárias no mercado de bens e serviços, bem como acarreta pressões inflacionárias no mercado de trabalho. Dentro deste contexto, a taxa de desemprego é utilizada para que se possa analisar o comportamento futuro da inflação e avaliar medidas de política econômica.

A NAIRU $^{30}$ (non-accelerating-inflation rate of unemployment), figura proeminente na Curva de Phillips, incorpora um trade-off entre as taxas de desemprego e de inflação. Assim, a variação da inflação depende da diferença entre as taxas de desemprego corrente e natural. Quando a taxa de desemprego corrente ultrapassa a taxa natural, a inflação diminui; já quando o desemprego corrente é menor do que a taxa natural, a inflação aumenta (Blanchard, 2001).

Dentro deste contexto, é importante mencionar a grande controvérsia existente em teoria econômica diz respeito à eficácia de se utilizar o conceito da NAIRU como instrumento de tomada de decisão por parte da autoridade monetária. A objeção teórica se vale da premissa de que o trade-off entre inflação e desemprego é instável ao longo do tempo, fazendo com que esta taxa sofra continuamente mutações em razão de fatores demográficos, relativos à produtividade dos fatores, etc. Logo, considerando, por exemplo, um aumento da produtividade do trabalho, este movimento provocaria um aumento do produto real, que conseqüentemente reduziria a taxa de desemprego. No entanto, se o Banco Central interpretar, dentro do contexto exposto, esta queda do desemprego como sendo associada a pressões inflacionárias, então a política monetária seria conduzida por interpretações equivocadas, o que provocaria distorções desnecessárias na economia. Os críticos argumentam a NAIRU é um indicador difícil de se prever com exatidão. Esta possibilidade ilustra a dificuldade de se interpretar variações na taxa de desemprego como instrumento no combate a inflação.

Comparando as taxas de desemprego das últimas décadas, verifica-se que durante os anos 60 ela foi de 4,4\%, passando para 6,2\% nos anos 70, 7,2\% nos anos 80 e chegando a 6,2\% nos 90. Segundo Baker (2002) ${ }^{31}$, a NAIRU Americana situa-se em 4\% (dados de 2001).

\footnotetext{
${ }^{30} \mathrm{O}$ debate a respeito da regra ótima de política monetária é baseado na pressuposição da existência da NAIRU, no entanto é difícil de demonstrar a existência desta taxa empiricamente.

31 Co-Director of the Center for Economic and Policy Research em Washington
}

76

Economia \& Tecnologia, Ano 01 - Vol. 03 - Set / Out / Nov/ Dez de 2005 
Por outro lado, um recente estudo da OCDE (2003) ${ }^{32}$ revelou que a NAIRU dos Estados Unidos para o ano de 2003 foi de 5,1\%.

Os modelos de previsão de inflação são extremamente valiosos aos banqueiros centrais para que se possa combater com eficácia a inflação. Como se viu, os modelos que incorporam o conceito da NAIRU possuem problemas em identificar a natureza do choque na economia. Assim, como resposta teórica, foram desenvolvidos os modelos de previsão de inflação utilizando o método $\mathrm{VAR}^{33}$. No entanto, todos os modelos que trabalham com previsão estão sujeitos a erros. Neste contexto, a questão relevante é: dentre as duas classes de modelos, quais apresentam os melhores resultados? Assim, não basta argumentar que os modelos baseados na NAIRU apresentam erros, mas sim mostrar que as incertezas presentes neste tipo de modelagem são maiores do que as baseados no modelo VAR. De acordo com Judd (1997), as evidências empíricas não mostram superioridade da modelagem VAR sobre a abordagem baseada na NAIRU. Desta forma, verifica-se o porque dos policy makers darem especial atenção a variáveis como taxa de desemprego como instrumento de política monetária e, em particular, as alterações da NAIRU.

O FED trabalha, dentro deste contexto, para evitar que haja perdas demasiadas no crescimento econômico e no nível de emprego, além de garantir baixas taxas de inflação. Assim, na prática, os dados de curto prazo dessas variáveis são utilizados como guias no processo de tomada de decisões.

De acordo com Taylor (1993a, 1993b) ${ }^{34}$, a pergunta chave a se deve fazer em política monetária é que tipo de regra o Banco Central deve usar para orientar sua tomada de decisão. Mais precisamente, que tipo de resposta a decisão de elevar ou reduzir a taxa de juros deve ser capaz de dar ao controle da inflação. Assim, a chamada "regra de Taylor" propõe que:

a) A taxa de juros dos Fundos Federais deve ser sempre ajustada de modo a reagir às diferenças entre os desempenhos efetivo e desejado no tocante ao duplo objetivo estabelecido pelo FED, ou seja, estabilidade de preços e pleno emprego.

\footnotetext{
32 "Structural unemployment, wage shares and unit labor costs - Illustration"

33 Vetor auto-regressivo (VAR).

34 Taylor mostrou que durante o período de 1984 e 1992 a regra de política monetária adotada pelo Federal Reserve foi conduzida de tal forma que o a taxa de juros Em seu artigo de 1993, Taylor analisou o comportamento da política monetária americana durante o período de 1984-1992, e procurou mostrar que a as regras que ditam tal política são determinadas, de tal forma, que a taxa de juros dos títulos federais se ajustavam aproximadamente de forma a garantir dois resultados conjuntos de desempenho: baixa inflação e crescimento.
} 
b) O Banco Central deve elevar a taxa de juros sempre que a inflação estiver acima da meta (mesmo que esta seja uma meta implícita) ou quando a economia estiver operando acima de seu produto potencial. Raciocínio análogo vale para quando a inflação estiver abaixo da meta, ou se o produto estiver abaixo do seu nível potencial. No entanto, percebe-se claramente que os objetivos de crescimento com pleno emprego e inflação baixa são muitas vezes conflitantes. Assim, a autoridade monetária deve ser capaz de balancear a taxa de juros a fim de obter simultaneamente os dois objetivos. Embora o Federal Reserve não siga explicitamente esta regra, estudos empíricos mostram que ela foi capaz de descrever o comportamento da política monetária durante o período Greenspan.

\subsection{Visão Geral da Economia}

De fato, na última década a performance macroeconômica dos Estados Unidos mostra crescimento com taxas baixas de inflação, conforme observa-se no gráfico abaixo:

Gráfico 1. Variação \% anual - Produto, taxa de juros e taxa de inflação (1994-2004)

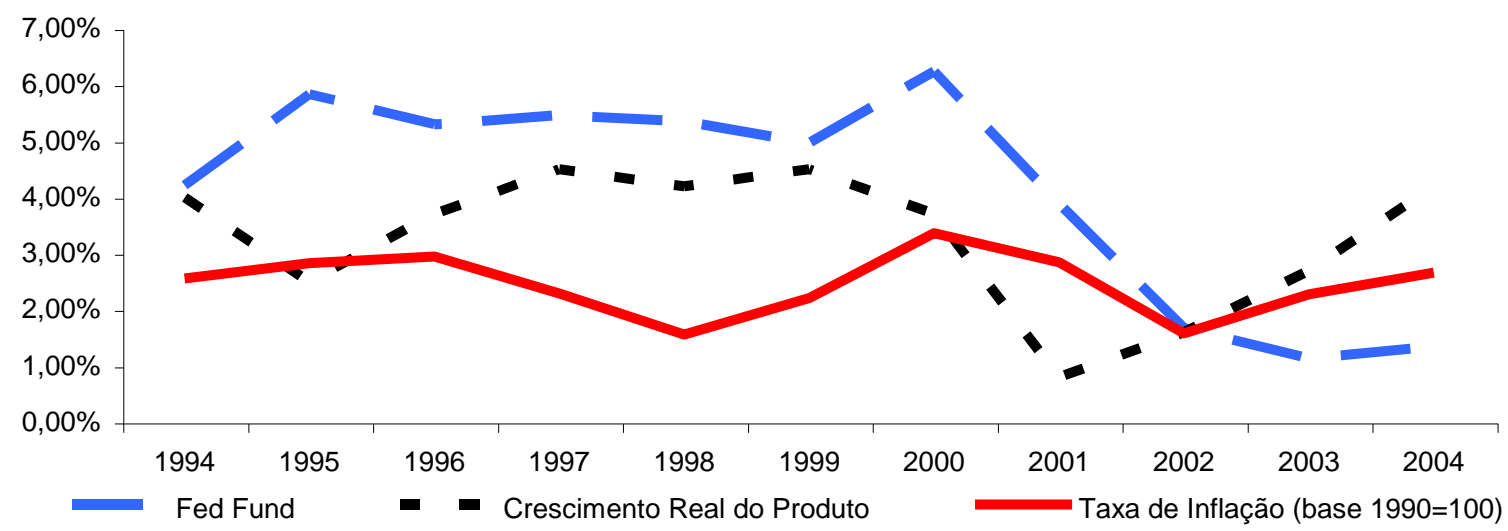

Fonte: Federal Reserve, Bureau of Labor Statistics, elaboração própria.

De acordo com este referencial, a adoção de metas de inflação implícita não significa a falta de preocupação com resultados econômicos como produto e desemprego. A idéia de uma meta quantitativa para a inflação está amparada pelo fato da política monetária ser capaz, no longo prazo, de determinar a inflação média de um país, mas incapaz de determinar seu produto médio e nível de emprego ${ }^{35}$ (Friedman, 2000).

\footnotetext{
35 No longo prazo a quantidade de bens e serviços produzidos pela economia e o número de trabalhadores empregados dependem, em última instância, de fatores como tecnologia e a propensão a poupar da sociedade.
}

78 
É importante mencionar, também, um aspecto microeconômico de extrema relevância, o chamado hiato do produto. Esta medida diz qual a distância que se encontra a produção atual da produção máxima que pode ser atingida sem que, com isso, haja ganhos de margem de lucros. Tecnicamente, esta medida informa qual a diferença entre o produto efetivo e o produto potencial. De acordo com Sicsú e Oliveira (2003), é possível definir, embora arbitrariamente, limites quantitativos em economia, ao se sugerir que um setor somente teria uma política de preços de ganhos de margem quando o seu nível de utilização de capacidade instalada ocupasse mais que um terço da sua capacidade ociosa média (período 1972-2004). Segundo o critério desses autores, considerando, por exemplo, a média histórica da indústria americana, que é de 79,35\%, somente se a capacidade utilizada ultrapassar 87,33\% $(79,35+20,35 / 3=87,33)$ é que haveria incentivos para se praticar uma política de aumento de margem de lucro (Ver Quadro 1 em anexo).

Assim, no caso norte-americano nenhum setor adentrou a faixa crítica no segundo trimestre de 2005. Segundo dados do Bureau Economic Analysis (BEA) - gráficos 2 e 3 - no terceiro trimestre de 2005, o produto real cresceu à taxa anualizada de 3,8\%, acumulando uma série de 30 meses crescendo acima dos 3\% a.a.. Além disso, é o melhor desempenho entre o Grupo do G-7, que inclui, além dos Estados Unidos, Alemanha, Canadá, França, Itália, Japão e Reino Unido. Este resultado reflete o vigor do crescimento do produto puxado principalmente pelo consumo das famílias e pela retomada do ritmo de investimento privado, que havia recuado no segundo trimestre do corrente ano.

\section{Gráfico 2. Produto real em dólares correntes, ajuste sazonal - base 2000}

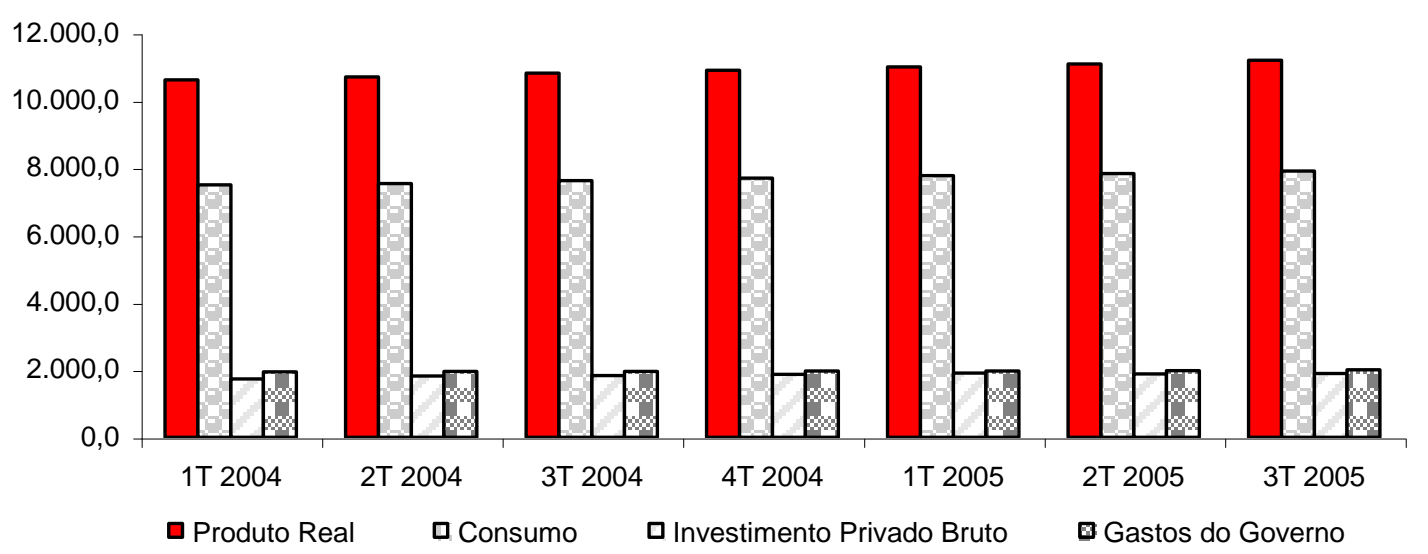

Fonte: Bureau of Economic Analysis, elaboração própria. 


\section{Gráfico 3. Variação percentual real com respeito ao período anterior}

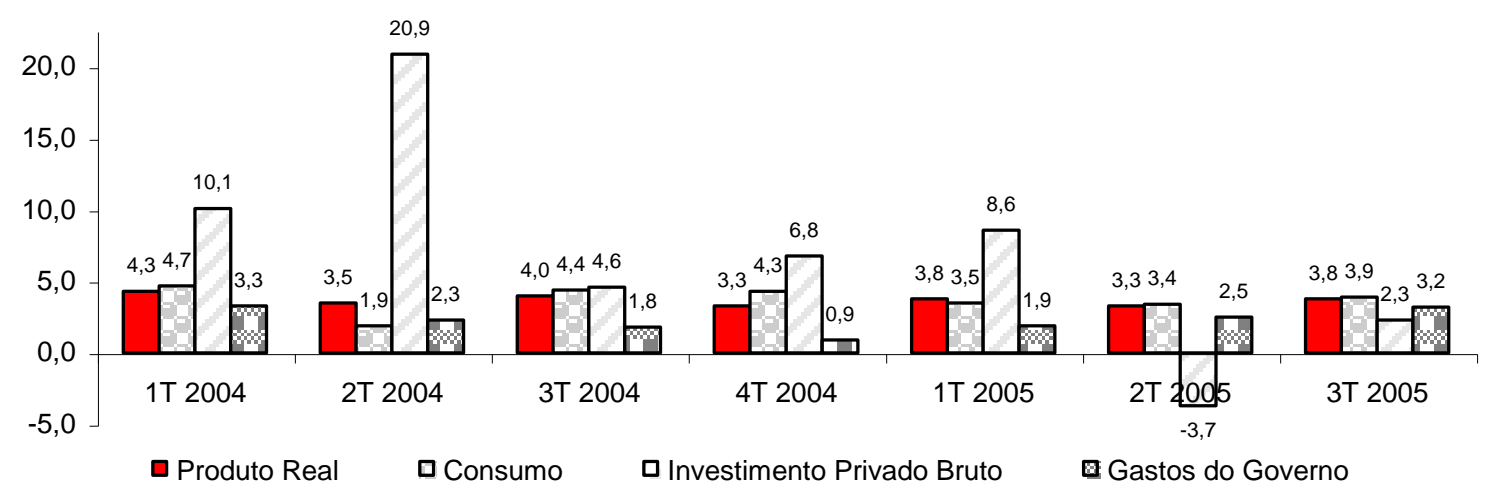

Fonte: Bureau of Economic Analysis, elaboração própria.

O papel do investimento no nível de atividade econômica deve ser interpretado levando em conta o seu duplo papel dentro da economia. Por um lado, ele é componente da demanda agregada, por outro, é responsável pelo crescimento da capacidade produtiva do país. Assim, dentro da conta investimento, destaca-se a construção residencial que registrou crescimento de 10,8\%, após crescer 9,5\% no segundo trimestre, e contribuiu com 0,62 pontos percentuais no crescimento real do produto.

De acordo com o gráfico 4, pode-se observar claramente que o ritmo de investimento continua elevado, o que demonstra o vigor do crescimento da economia norte-americana, sinalizando que a fase de expansão do PIB ainda continua com força. Dados do segundo trimestre de 2005 mostram que o investimento privado americano foi da ordem de 16,6\% do PIB, contra uma média de 15,97\% dos últimos 20 trimestres.

\section{Gráfico 4. Investimento Privado Bruto como proporção do PIB}

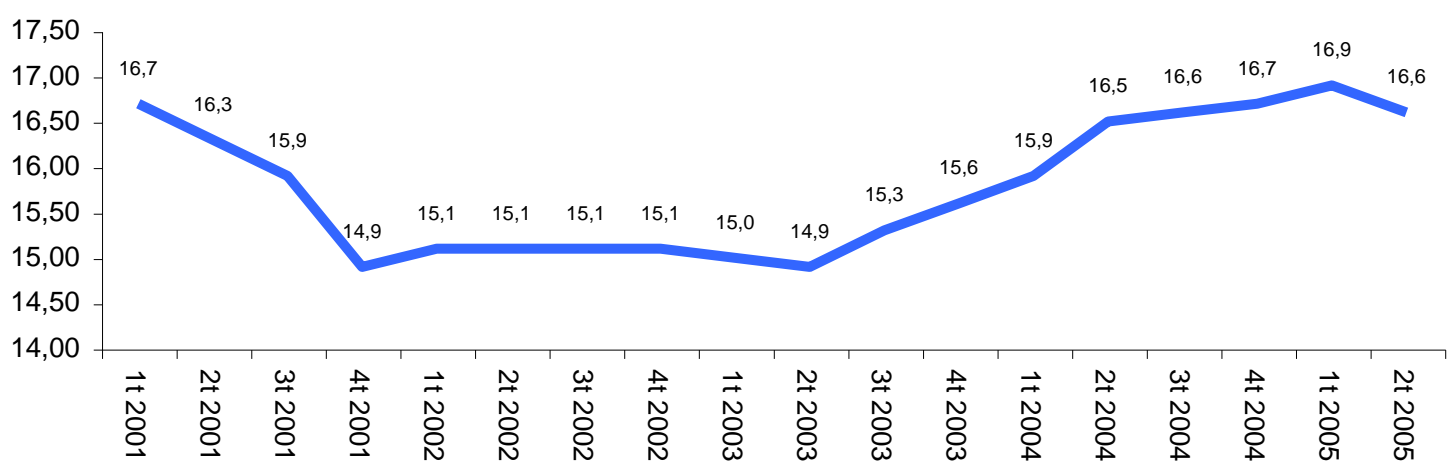

Fonte: Bureau of Economic Analysis, elaboração própria.

Uma rápida passada pelo mercado de trabalho - gráfico 5 - mostra que a taxa de desemprego encontra-se em trajetória descendente desde junho de 2003, registrando 5,1\% em 80 
setembro de $2005^{36}$, pouco abaixo da média dos últimos 60 meses, que foi de 5,37\%, corroborando com os dados de crescimento do produto. A grande pergunta que deve ser feita, dentro deste contexto é qual a taxa de desemprego não aceleradora da inflação (NAIRU).

\section{Gráfico 5. Taxa de desemprego total da força de trabalho}

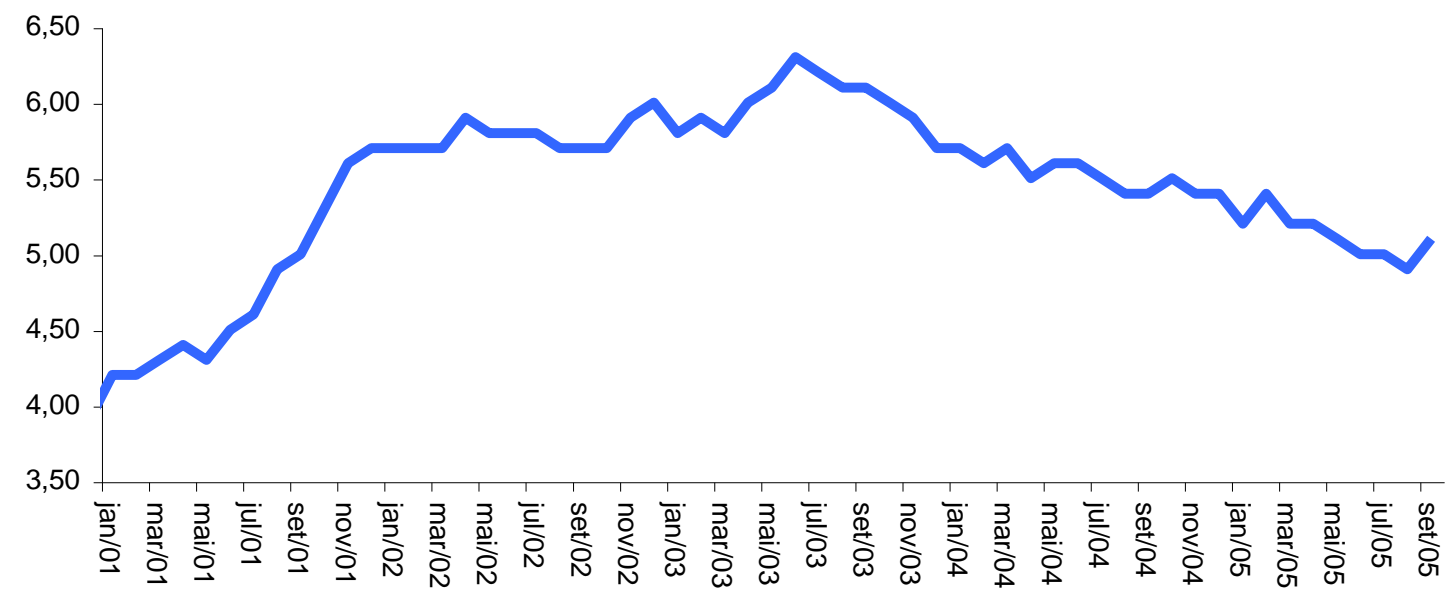

Fonte: Bureau of Labor Statistics, elaboração própria.

Apesar da grande controvérsia a respeito da "verdadeira" NAIRU americana, para efeitos de política monetária é importante verificar qual o comportamento recente do custo da mão-de-obra. Este indicador sintetiza informações como: os ganhos de produtividade, pressões inflacionárias ou mesmo retração da atividade econômica. O que se observa pelo gráfico 6 é que o custo da mão-de-obra nos Estados Unidos vem caindo de forma acentuada desde o segundo trimestre de 2004. Assim, pode-se dizer que este ciclo de crescimento tem se baseado primordialmente por ganhos de produtividade. Mais ainda, os dados confirmam que a taxa de desemprego dos Estados Unidos pode cair ainda mais, sem que com isso haja pressões inflacionárias.

\footnotetext{
${ }^{36}$ Segundo relatório de 07/10/2005 divulgado pelo Bureau of Labor Statistics, a elevação da taxa de desemprego em setembro é explicada, principalmente, pelos efeitos dos Furacões Katrina e Rita. Assim, esta queda não pode ser interpretada como uma desaceleração da criação de postos de trabalho.
} 


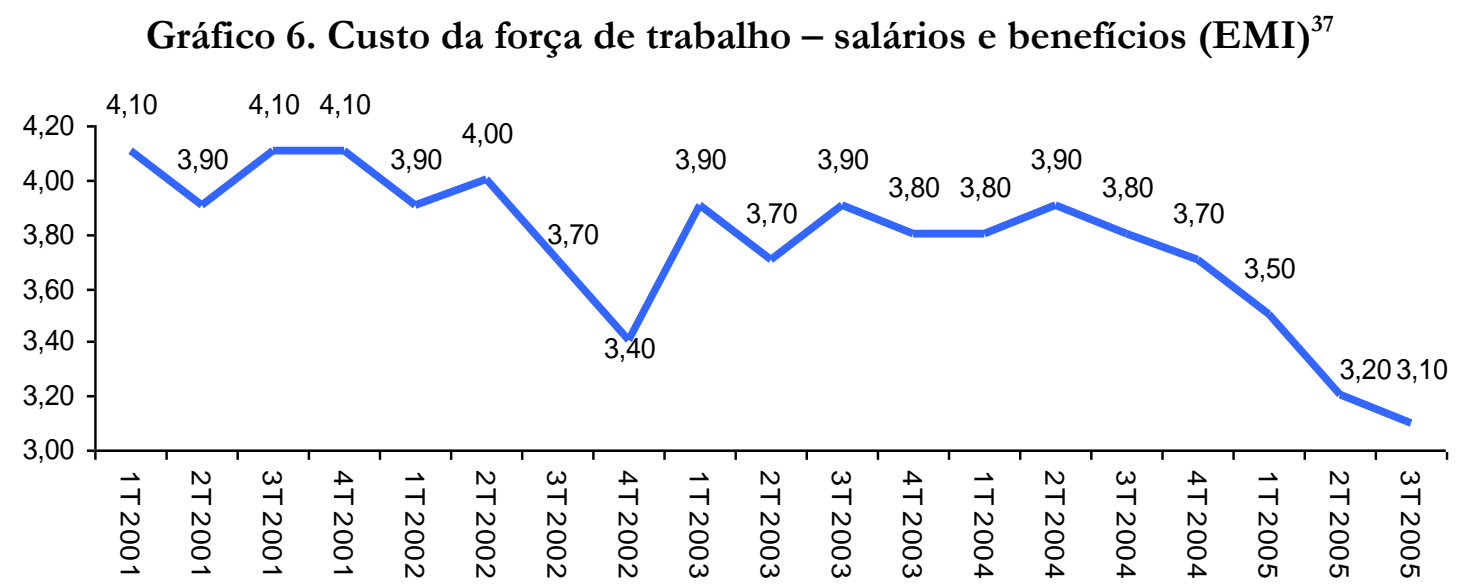

Fonte: Bureau of Labor Statistics, elaboração própria.

Conclui-se, portanto, que apesar dos preços de energia mais elevados, a economia americana pode continuar de forma sólida o crescimento sustentado do produto. Segundo dados da OCDE ${ }^{38}$, espera-se que para os próximos 18 meses o produto dos Estados Unidos crescerá 3,25\% aproximadamente.

No entanto, este mesmo relatório chama atenção para possíveis riscos. Dentre eles, destacam-se a possível escalada dos preços do petróleo, que poderia fazer com que a inflação subisse para um patamar acima do desejável, o crescimento do déficit externo americano que atingiu o patamar de 6\% do PIB no terceiro trimestre de 2005 e, por último, tem-se ainda a preocupante bolha do setor imobiliário com forte efeito sobre a riqueza e o consumo das famílias $^{39}$. É importante frisar que nenhum destes três fatores afetaram de forma significativa o desempenho da economia norte-americana até o presente momento.

\subsection{A Questão da bolha imobiliária norte-americana}

Contudo, a economia é muito mais complexa do que crescimento, inflação e desemprego. De acordo com a teoria neoclássica tradicional, os mercados financeiros desempenham o papel primordial de compartilhamento de risco e eficiência de informações, de modo que os preços dos ativos são capazes de alocar de forma mais eficiente os recursos e transmitir todas as informações relevantes do mercado. Em teoria, os preços deveriam refletir

\footnotetext{
${ }^{37}$ Employment Cost Index

${ }^{38}$ Economic Survey of the United States (2005).

${ }^{39}$ Este tópico será tratado com mais rigor no final deste artigo.
} 


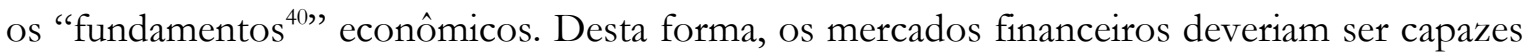
de distinguir movimentos de especulação de preços, euforia e mesmo depressão irracional por parte dos investidores. Esses componentes "não fundamentados" são denominados de bolhas, cujo processo de expansão pode conduzir a economia a um sério colapso, provocando severas tensões no mercado financeiro e desestabilizando-a. Assim, o estouro de uma bolha de preços pode afetar gravemente a performance macroeconômica dos países.

Apesar destes problemas potenciais, a literatura econômica ainda não foi capaz de fornecer uma resposta apropriada sobre qual deveria ser o papel da autoridade monetária frente evidências de bolhas nos mercados financeiros. Portanto, este é mais um dos dilemas que os bancos centrais enfrentam na atualidade. Alguns autores argumentam que a política monetária deveria ser utilizada visando conter ou reduzir o risco de explosão da bolha, sendo que o objetivo final seria amenizar as conseqüências adversas da economia. Uma outra corrente, por sua vez, argumenta que a utilização do instrumento monetário geraria incertezas no mercado e, dado o pouco conhecimento sobre o comportamento das bolhas, provocaria distorções ainda mais maléficas.

Neste sentido, duas políticas monetárias poderiam ser utilizadas. A primeira, definida como "política padrão", defende que o Banco Central só deveria elevar a taxa básica de juros se a trajetória futura da taxa de inflação fosse diferente da trajetória considerada ideal pela autoridade monetária. A segunda política, "política de bolha", defende que os componentes da bolha possuem uma dinâmica perniciosa e, portanto, é essencial combater as possíveis conseqüências adversas utilizando gradualmente o instrumento de elevação da taxa de juros alterando os preços relativos da economia. Desta forma, a política monetária seria capaz de reduzir, ou mesmo eliminar de forma gradual a bolha. Assim, os efeitos adversos de curtíssimo prazo provocados pela elevação da taxa de juros são vistos como um instrumento de prevenção sobre um mal maior.

A diferença fundamental entre as duas políticas diz respeito ao diagnóstico. Enquanto a primeira trata o componente de bolha como sendo essencialmente um choque exógeno no sistema, a segundo política o examina como sendo endógeno. A decisão entre qual a melhor política a ser adotada passa por três perguntas básicas:

\footnotetext{
${ }^{40} \mathrm{O}$ valor fundamentado de um ativo é o valor atual do retorno real esperado para o futuro, descontado pelas taxas reais de juros de um ano esperadas para o futuro. Se não houver bolhas, nem preferências conjunturais, o preço do ativo será igual ao seu valor fundamentado.
} 
a) Os policy makers podem identificar a presença de bolhas nos mercados financeiros?

b) Caso a bolha estoure, quais serão os efeitos adversos na economia?

c) A política monetária é o melhor instrumento para esvaziar uma bolha?

Para a primeira pergunta, alguns autores argumentam que os mercados financeiros são alinhados com os fundamentos econômicos, portanto as bolhas simplesmente não existem. Eles argumentam ainda que, mesmo admitindo a possibilidade de bolhas nos mercados, os instrumentos disponíveis não seriam capazes de captá-las. Logo, se os policy makers não são capazes de discernir um processo de elevação fundamentado de preços de um não fundamentado, então a política padrão seria a mais recomendável.

Mas, supondo que as bolhas de preços possam ser identificadas, então o próximo passo reside em analisar se as flutuações de preços têm impacto significativo que a política monetária não possa ser capaz de remediar através de seus instrumentos. Assim, se a bolha estiver em um mercado pequeno, localizado, então tentativas de realinhamento de preço deveriam ser descartadas. Neste caso, a autoridade monetária deveria adotar a primeira política. Outra situação que se recomenda o uso da primeira política são flutuações no componente de bolha que tenham efeitos convencionais sobre a demanda. Nestas situações, as defasagens temporais são equivalentes às defasagens temporais existentes no mecanismo de transmissão da política monetária.

Alternativamente, movimentos de preços podem afetar significativamente o desempenho da economia, com conseqüências duras de se combater com o instrumental monetário. Esta possibilidade diz respeito a estouro da bolha em mercados de recursos financeiros capazes de conduzir a economia a uma crise financeira e um crash de créditos de longo prazo. Uma instabilidade financeira de tal magnitude é capaz de provocar contágios e transmitir a crise para outros setores da economia. Um exemplo deste tipo de crise foi evidenciado pela crise das dot com. Naturalmente, é difícil resolver os problemas causados pelo estouro da bolha através dos instrumentos monetários. Neste sentido, a estratégia "política de bolha é preferível".

O último obstáculo na estratégia de combate à bolha diz respeito à eficácia do instrumento monetário. A política monetária controla principalmente a taxa de juros de curto prazo atuando principalmente sobre o sistema bancário. Assim, o mecanismo de elevação da taxa de juros afeta diretamente o preço dos ativos e a liquidez do sistema financeiro. Mais precisamente, ele afeta toda a curva de rendimentos (yield curve) da economia, afetando as taxas 
de curto, médio e longo prazo. A curva de rendimentos descreve a relação entre estas taxas para cada ponto do tempo.

Em primeiro lugar, sabe-se que alterações na taxa de juros de curto prazo afetam as expectativas dos agentes a respeito da trajetória de crescimento da economia e de seus lucros. Em segundo lugar, as decisões de política monetária afetam a taxa de desconto que os agentes aplicam em seus rendimentos futuros, afetando o VPL de seus investimentos. Por fim, movimentos na taxa de juros induzem a mudanças nos portfólios dos agentes, o que acarreta alterações nos preços relativos da economia. Para sintetizar o argumento, mudanças nos preços afetam a riqueza dos agentes, que por sua vez possui forte impacto sobre as decisões de consumo e investimento, importantes componentes da demanda agregada. Logo, pode-se afirmar que a política monetária é eficaz no combate à bolha de preços nos mercados financeiros.

Recentemente, a possibilidade de uma bolha de preços no mercado imobiliário americano tem chamado a atenção de muitos analistas. Esta bolha pode ser definida como um desvio não fundamentado dos preços reais dos ativos dos cobrados de fato pelo mercado. No entanto, esta definição é de difícil mensuração, uma vez que os preços reais são difíceis de se mensurar e muitas vezes não são observáveis. Assim, é necessário identificar alguns indicadores que comprovem este deslocamento de preços.

De acordo com dados do U.S Bureau of Labor Statistics, de 1950 a 1995, os preços dos imóveis cresciam aproximadamente à mesma taxa que outros bens e serviços como automóveis, gás e saúde. Entretanto, a partir de 1996, o mercado imobiliário tem crescido em torno de 45\% acima da inflação. Este processo inflou em mais de US\$5 trilhões o mercado, considerando os preços balizados pela trajetória histórica do mercado.

Seria de esperar, portanto, que este processo de elevação dos preços imobiliários fossem ser acompanhados de significativos aumentos nos valores pagos pelos aluguéis, já que historicamente, pode-se afirmar que aluguéis e preços dos imóveis sempre cresceram a taxas semelhantes.

Segundo o Office of Federal Housing Enterprise Oversight (OFHEO), apesar do desaquecimento que a economia americana sofreu entre o segundo quarto de 2001 e o terceiro quarto de 2002, o mercado imobiliário sofreu uma elevação de 7\% ao ano, comparando-se com a última recessão de 1990-1991, quando os preços se elevaram a uma taxa anualizada de $2 \%$, muito mais modesta. Segundo Friedman, considerando que os preços imobiliários estão crescendo mais rapidamente que o aumento dos postos de trabalho, 
rendimento pessoal, confiança do consumidor e demais condições macroeconômicas da economia, então o mercado pode, de fato, estar diante de uma bolha.

De acordo com os dados do gráfico 7 , pode-se observar claramente a divergência entre os preços dos imóveis dos preços dos alugueis a partir do segundo trimestre de 1995.

\section{Gráfico 7. Índice de preços dos imóveis/aluguéis}

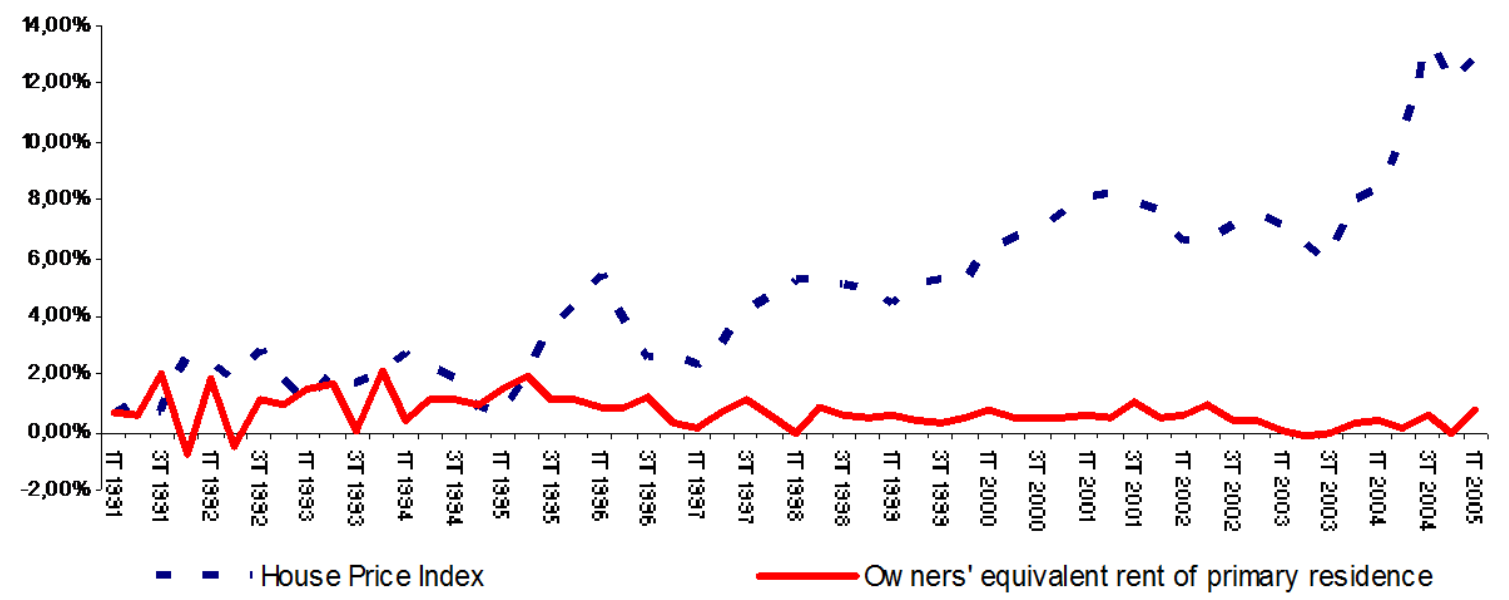

Fonte: OFHEO, Bureau of Labor Statistics, elaboração própria.

No entanto, o que leva os investidores a pagarem um preço superior ao chamado preço fundamentado? Sob que condições pode ocorrer este descompasso de preços. A resposta surpreendente é que ele pode ocorrer mesmo que os investidores estejam bastante atentos quanto ao comportamento do mercado e mesmo havendo a possibilidade de ganhos de arbitragem. Esse processo de bolhas sugere que os preços dos imóveis sobem simplesmente pelo fato de que o mercado espera que eles subam. Esses movimentos são denominados de bolhas especulativas racionais (Blanchard, 2001). A lógica por trás deste argumento é de que os agentes podem estar dispostos a pagar mais do que o valor fundamentado se esperarem que o preço possa subir ainda mais no futuro.

Outro ponto importante na análise diz respeito à participação de $5 \%$ da construção imobiliária no PIB americano. O Fundo Monetário Internacional ${ }^{41}$ comparou o efeito de um crash imobiliário frente a um de origem bursátil. Um crash bursátil, definido como uma queda superior a 30\% nos preços das ações, "custa" o equivalente a 4\% do crescimento do PIB em dois anos. Enquanto que um crash imobiliário, definido como uma queda nos preços superior

${ }^{41}$ World Economic Outlook, abril de 2005.

86 
a 14\%, produz danos similares a uma queda de $8 \%$ no PIB. E, além disso, seus efeitos duram muito mais: até quatro anos.

\subsection{Conclusão}

Conclui-se, portanto, que o Federal Reserve conduz a política monetária com o claro objetivo de atender as necessidades domésticas. O cenário atual mostra que o maior risco no momento diz respeito a um possível superaquecimento da economia (no médio prazo) e uma possível ruptura da bolha de preços no mercado imobiliário. Desta forma, faz-se necessário elevar gradualmente a taxa básica de juros calibrando o crescimento econômico com os objetivos inflacionários. Pode-se afirmar, também, que a elevação da taxa de juros minimiza os riscos de um crash imobiliário com conseqüências alarmantes para a economia norteamericana e mundial. Além destas variáveis o FED terá que enfrentar, ainda, os desafios lançados pela escalada do preço do petróleo no mercado mundial, controlar o desequilíbrio fiscal, e evitar o crescimento desenfreado do déficit em transações correntes, muito embora, os chamados déficits gêmeos estejam fora da alçada do Banco Central. No entanto, as últimas atas das reuniões do $\mathrm{FOMC}^{42}$ deixam clara a preocupação da deterioração dos indicadores de vulnerabilidade da economia americana, indicando, com isso, a necessidade de um conjunto de medidas fiscais atuando em conjunto com as monetárias, visando o desempenho de longo prazo da economia.

${ }^{42}$ Comitê de mercado aberto do Federal Reserve. 


\section{Referências Bibliográficas}

Baker, D. (2002). Alan Greenspan and the ECB: Different Policies, Different Results.

Center for Economic and Policy Research. Federal Reserve

Blanchard, O (2001). Macroeconomia. Prentice-Hall: Londres

Blanchard, O; Fisher, S. (1989) Lectures in Macroeconomics. Cambridge, MIT Press.

Friedman, B. M (2000). Monetary Policy. NBER Working Paper Series, Cambridge, MA,working paper 8057, December

FMI (2005). World Economic Outlook, abril.

Greenspan, A. (1996). Remarks by Chairman Alan Greenspan at the Annual. Dinner and Francis Boyer Lecture of The American Enterprise Institute for Public Policy Research, Washington, D.C.

Judd, J.P. (1997). NAIRU: Is it Useful for Monetary Policy? FRBSF Economic Letter, Federal Reserve Bank of San Francisco.

Sicsú, J., Oliveira, S. (2003). Taxa de juros e controle da inflação no Brasil. In. Sicsú, J., Oreiro, J. L., Paula, L. F. de (2003). Agenda Brasil: políticas econômicas para o crescimento com estabilidade de preços. Rio de Janeiro: Konrad Adenauer/São Paulo: Editora Manole.

OCDE (2005). Economic Survey of the United States (2005).

OCDE (2003). Structural unemployment, wage shares and unit labor costs. OECD Economic

Outlook.

Taylor, J. (1993a). Discretion Versus Policy Rules in Practice. Carnegie-Rochester Conference Series on Public Policy 39, pp. 195-214.

Taylor, J. (1993b), Macroeconomic Policy in World Economy: From Econometric Design to Practical Operation, New York: W.W.Norton. 


\section{Anexo}

Quadro 1. Percentual do grau de utilização da capacidade produtiva, ajuste sazonal

\begin{tabular}{|c|c|c|c|c|c|c|c|c|c|}
\hline Indústria/Ano & $\begin{array}{l}\text { Média } \\
1 \mathrm{~T}\end{array}$ & $\begin{array}{l}\text { Média } \\
2 \mathrm{~T}\end{array}$ & $\begin{array}{c}\text { Média } \\
\text { 3T }\end{array}$ & $\begin{array}{l}\text { Média } \\
4 \mathrm{~T}\end{array}$ & $\begin{array}{c}\text { Média } \\
1972- \\
2004 \\
\end{array}$ & $\begin{array}{c}\text { Média } \\
2004\end{array}$ & $\begin{array}{c}\text { Média } \\
2005\end{array}$ & $\begin{array}{l}\text { Produto } \\
\text { Potencial }\end{array}$ & $\begin{array}{l}\text { Hiato do } \\
\text { Produto }\end{array}$ \\
\hline \multicolumn{10}{|c|}{ Total Indústria } \\
\hline 2004 & 77,33 & 77,92 & 78,19 & 78,82 & 81,00 & 78,06 & 79,35 & 87,33 & 7,95 \\
\hline 2005 & 79,30 & 79,36 & 79,38 & & & & & & \\
\hline \multicolumn{10}{|c|}{ Manufaturados (Classificação Geral) } \\
\hline 2004 & 75,62 & 76,51 & 77,03 & 77,65 & 79,80 & 76,70 & 78,15 & 86,53 & 8,30 \\
\hline 2005 & 78,15 & 78,07 & 78,24 & & & & & & \\
\hline \multicolumn{10}{|c|}{ Manufaturados (NAICS) } \\
\hline 2004 & 75,09 & 75,94 & 76,45 & 77,11 & 79,60 & 76,15 & 77,53 & 86,40 & 8,71 \\
\hline 2005 & 77,51 & 77,38 & 77,69 & & & & & & \\
\hline \multicolumn{10}{|c|}{ Manufaturados Duráveis (NAICS) } \\
\hline 2004 & 73,12 & 73,79 & 74,44 & 75,16 & 78,00 & 74,13 & 75,72 & 85,33 & 9,16 \\
\hline 2005 & 75,60 & 75,37 & 76,18 & & & & & & \\
\hline \multicolumn{10}{|c|}{ Manufaturados não-duráveis } \\
\hline 2004 & 77,77 & 78,90 & 79,25 & 79,85 & 81,80 & 78,94 & 80,11 & 87,87 & 7,97 \\
\hline 2005 & 80,21 & 80,23 & 79,90 & & & & & & \\
\hline \multicolumn{10}{|c|}{ Outros Manufaturados (non-NAICS) } \\
\hline 2004 & 85,33 & 87,02 & 87,62 & 87,57 & 84,90 & 86,88 & 89,51 & 89,93 & 1,89 \\
\hline 2005 & 89,87 & 90,63 & 88,04 & & & & & & \\
\hline \multicolumn{10}{|c|}{ Mineração } \\
\hline 2004 & 87,29 & 86,63 & 86,27 & 85,61 & 87,10 & 86,45 & 86,81 & 91,40 & 6,82 \\
\hline 2005 & 87,52 & 88,33 & 84,58 & & & & & & \\
\hline \multicolumn{10}{|c|}{ Utilidades (eletricidade e gás) } \\
\hline 2004 & 86,33 & 85,10 & 83,71 & 85,42 & 86,80 & 85,14 & 85,52 & 91,20 & 4,15 \\
\hline 2005 & 84,43 & 85,07 & 87,05 & & & & & & \\
\hline \multicolumn{10}{|c|}{ Indústrias Selecionadas de Alta Tecnologia } \\
\hline 2004 & 68,02 & 69,69 & 69,92 & 69,80 & 78,30 & 69,36 & 72,57 & 85,53 & 11,37 \\
\hline 2005 & 71,84 & 71,70 & 74,16 & & & & & & \\
\hline \multicolumn{10}{|c|}{ Computador e Equipamentos periféricos } \\
\hline 2004 & 75,09 & 74,17 & 73,67 & 75,87 & 78,40 & 74,70 & 79,43 & 85,60 & 5,17 \\
\hline 2005 & 78,17 & 79,68 & 80,43 & & & & & & \\
\hline \multicolumn{10}{|c|}{ Equipamentos de Comunicação } \\
\hline 2004 & 52,79 & 53,67 & 56,71 & 58,78 & 76,00 & 55,49 & 64,73 & 84,00 & 15,79 \\
\hline 2005 & 62,29 & 63,68 & 68,21 & & & & & & \\
\hline \multicolumn{10}{|c|}{ Semicondutores e Equipamentos Relacionados } \\
\hline 2004 & 77,28 & 80,46 & 78,52 & 75,61 & 81,10 & 77,97 & 76,19 & 87,40 & 10,38 \\
\hline 2005 & 76,57 & 74,98 & 77,02 & & & & & & \\
\hline \multicolumn{10}{|c|}{ Grupos do Estágio Produtivo } \\
\hline \multicolumn{10}{|c|}{ Processamento de Matérias-Primas Cruas (capacidade) } \\
\hline 2004 & 85,30 & 85,76 & 85,75 & 85,49 & 86,40 & 85,57 & 85,29 & 90,93 & 8,02 \\
\hline 2005 & 86,49 & 86,46 & 82,92 & & & & & & \\
\hline \multicolumn{10}{|c|}{ Primários e Semi-acabados (capacidade) } \\
\hline 2004 & 79,38 & 79,78 & 79,69 & 80,17 & 82,10 & 79,75 & 80,18 & 88,07 & 7,76 \\
\hline 2005 & 80,30 & 79,95 & 80,30 & & & & & & \\
\hline \multicolumn{10}{|c|}{ Processamento Final (capacidade) } \\
\hline 2004 & 73,27 & 74,12 & 74,92 & 75,96 & 77,90 & 74,57 & 77,31 & 85,27 & 7,35 \\
\hline 2005 & 76,71 & 77,28 & 77,92 & & & & & & \\
\hline
\end{tabular}

Fonte: Bureau of Economic Analysis, elaboração própria. 
